\title{
Anchoring Samarium Oxide Nanoparticles on Reduced Graphene Oxide for High-Performance Supercapacitor
}

\author{
Amin Shiralizadeh Dezfuli ${ }^{a}$, Mohammad Reza Ganjali ${ }^{a, b,},{ }^{*}$ Hamid Reza Naderi ${ }^{a}$ \\ ${ }^{a}$ Center of Excellence in Electrochemistry, Faculty of Chemistry, University of Tehran, Tehran, \\ Iran. \\ ${ }^{b}$ Biosensor Research Center, Endocrinology \& Metabolism Molecular-Cellular Sciences Institute, \\ Tehran University of Medical Sciences, Tehran, Iran. \\ *Corresponding author. \\ E-mail address: ganjali@khayam.ut.ac.ir (Mohammad Reza Ganjali).
}




\begin{abstract}
:
We have synthesized $\mathrm{Sm}_{2} \mathrm{O}_{3}$ nanoparticles ( $\mathrm{SmNs}$ ) and anchored them onto the surface of reduced graphene oxide (RGO) through a self-assembly thereof by utilizing a facile sonochemical procedure. The nanomaterials were characterized by means of powder X-ray diffraction (XRD), Field-emission scanning electron microscopy (FE-SEM), fourier transform infrared spectroscopy (FT-IR) spectra, and X-ray photoelectron spectroscopy (XPS). As the next step, the supercapacitive behavior of the resulting nanocomposites were investigated when used as electrode material, through with cyclic voltammetric $(\mathrm{CV})$, galvanostatic charge-discharge and electrochemical impedance spectroscopy (EIS) techniques. The SmNs decorated RGO (SmNRGO) nanocomposites were found to possess a specific capacitance (SC) of $321 \mathrm{~F} \mathrm{~g}^{-1}$ when used in a $0.5 \mathrm{M} \mathrm{Na}_{2} \mathrm{SO}_{4}$ solution as an electrolyte, in a scan rate of $2 \mathrm{mV} \mathrm{s}^{-1}$. The $\mathrm{SC}$ of the $\mathrm{SmN}-$ RGO based electrodes were also found to be $268 \mathrm{~F} \mathrm{~g}^{-1}$ at a current density of $2 \mathrm{~A} \mathrm{~g}^{-1}$ through galvanostatic charge-discharge tests. The outstanding properties of the SmN-RGOs were attributed to synergy of the high charge mobility of SmNs and the flexibility of the sheets of RGOs. Additionally, the nano-composite revealed a unique cycling durability (maintaining $99 \%$ of its SC even after 4000 cycles).
\end{abstract}

\title{
Keywords:
}

Samarium oxide, Graphene, Nanocomposites, Supercapacitor, Energy storage 


\section{Introduction}

Using high-tech energy storage devices such as supercapacitors, is one of the strategies adopted to meet the incremental demand for energy, in the modern world [1]. These devices enjoy the advantage of considerable energy density, the ability of fast charge/discharge, and long life cycles over the conventional capacitors [2-4]. Function of supercapacitors falls into two mechanisms, and the devices have hence been divided into two major categories, i.e. pseudocapacitors and electrical double-layer capacitors (EDLCs).

In the case of pseudo-capacitors, the electrode materials used to construct the electrodes include oxides of noble and transition metals or conducting polymers, while EDLCs mainly use carbonaceous materials such as carbon nano-tubes (CNTs) or graphene to the same end $[4,5]$. The latter group of electrode materials constitute a class with unique properties including very high conductivity, thermal and chemical stability, as well as considerable surface area [6].

The fact that graphene can be produced from reduced graphene oxide (RGO) via lowcost procedures, has boosted the interest placed on this material [7]. A further incident that has attracted a great deal of interest towards this material is the advent of decorating RGO with various nano-materials. The resulting hybrid nano-materials have a set of various properties that can be fine-tuned by altering the loading degree, as well as the nano-material loaded on the RGO sheets [7-15]. A group of materials used for the decoration of RGO are metal oxides like $\mathrm{MnO}_{2}, \mathrm{Mn}_{3} \mathrm{O}_{4}, \mathrm{RuO}_{2}, \mathrm{CeO}_{2}$ and $\mathrm{SnO}_{2}$, which result in avoiding losing the surface area of RGOs, which is the result of the restacking of the graphene sheets. Hence graphene sheets loaded with such nano-materials can lead to increased accessibility of the graphene surface through the spacing function of such nano-particles between the graphene sheets $[16,17]$. The open spaces created among the sheets this way, greatly drops the internal resistance of the material, facilitating the diffusion of the electrolytes throughout the electrodes based on such materials [18]. As a result of all these modifications on carbonaceous materials, the energy density and capacitance of supercapacitors has been found to greatly increase [2, 4, 17, 19-21].

Lanthanoid oxides or in other words rare earth oxides (REOs), have recently attracted a great deal of attention and scientific endeavour due to their widespread applications 
including ion glass industries, heterogeneous catalysis, electronics and fuel cells [22-26]. REOs are known to undergo two distinct types of chemical processes, i.e. redox and acid-base reactions [22, 27], and given their redox properties [22], REOs constitute a set of potential candidates for pseudo-capacitors.

The lanthanoid used in this research i.e. samarium adopts both +2 and +3 oxidation states $[22,28]$. The focus of the current work is to introduce a facile, green procedure for the preparation of $\mathrm{Sm}_{2} \mathrm{O}_{3}$ in the form of nano-particles and using them to construct $\mathrm{Sm}_{2} \mathrm{O}_{3}$ nanoparticles decorated $\mathrm{RGO}$ ( $\mathrm{SmN}-\mathrm{RGO}$ ) nanocomposites through mild sonochemical conditions. Given that the size of the $\mathrm{Sm}_{2} \mathrm{O}_{3}$ falls in the nanometer scale and hence the increased surface area, its redox activity is greatly enhanced. To more clearly understand the influence of the composition of the nanomaterial on the supercapacitive behavior of the material 3 distinct compositions with various $\mathrm{Sm}_{2} \mathrm{O}_{3} / \mathrm{RGO}$ ratios were prepared and investigated.

\section{Experimental}

\subsection{Materials}

Samarium(III) nitrate hexahydrate $\left(\mathrm{Sm}\left(\mathrm{NO}_{3}\right)_{3} \cdot 6 \mathrm{H}_{2} \mathrm{O}\right)$, poly(tetrafluoroethylene) (PTFE), hydrazine hydrate $\left(\mathrm{N}_{2} \mathrm{H}_{4}\right)$, Graphite flakes (cat \#332461), and ammonium hydroxide $\left(\mathrm{NH}_{4} \mathrm{OH}\right)$ were purchased from Sigma-Aldrich Co. Potassium permanganate $\left(\mathrm{KMnO}_{4}\right)$, sodium sulfate $\left(\mathrm{Na}_{2} \mathrm{SO}_{4}\right)$ and hydrogen peroxide $\left(\mathrm{H}_{2} \mathrm{O}_{2}\right)$ were purchased from Merck Chemical Co. Phosphoric acid $\left(\mathrm{H}_{3} \mathrm{PO}_{4}\right)$, sulfuric acid $\left(\mathrm{H}_{2} \mathrm{SO}_{4}\right)$ and hydrochloric acid $(\mathrm{HCl})$ were all purchased from Mojallali Chemical Co. Acetylene black (>99.9\%, S.A. $80 \mathrm{~m}^{2} \mathrm{~g}^{-1}$ ) was purchased from Alfa Aesar Co. All reagents were used without any further modification.

\subsection{Preparing the SmN-RGO nano-composites}

The SmN-RGO hybrid material was prepared through a facile sonochemical routine previously reported in other works $[16,21]$. The method generally involves the synthesis 
of $\mathrm{Sm}_{2} \mathrm{O}_{3}$ nanoparticles ( $\mathrm{SmNs}$ ); depositing the $\mathrm{SmNs}$ on the graphene oxide (GO) sheets; and finally reducing the loaded GO to RGO (Scheme 1).

In practice a 32\% ammonia solution, was slowly added into a solution of $\mathrm{Sm}\left(\mathrm{NO}_{3}\right)_{3} \cdot 6 \mathrm{H}_{2} \mathrm{O}$ under sonication in an ultrasonic bath (FALC instruments ultrasonic) for $60 \mathrm{~min}$. Then the resulting suspension was add-mixed with a suspension of GO and the sonication was started and continued for $20 \mathrm{~min}$. This was intended to anchor the nano-particles onto the GO sheets, which was followed by the final step of reducing GO to RGO through the addition of the reducing agent (i.e. $\mathrm{N}_{2} \mathrm{H}_{4}$ ). This way a black precipitate was formed which was subsequently dried at $60{ }^{\circ} \mathrm{C}$ for one day. The material formed under these conditions shall be referred to as SmN-RGO throughout the text. It is noteworthy that both pure $\mathrm{Sm}_{2} \mathrm{O}_{3}$ and RGO where prepared through the same procedure (i.e. GO was prepared starting from graphite flake powder using the Tour's method [29]). Table 1 presents a summary of the details of the $\mathrm{Sm}_{2} \mathrm{O}_{3} / \mathrm{RGO}$ ratios in the $\mathrm{SmN}$ RGO samples.

\section{Scheme 1.}

\subsection{Characterizations}

The crystallinity of the samples was evaluated through X-ray diffraction (XRD) using a Philips PW-1730 X-ray diffractometer equipped with $\mathrm{Cu}_{\alpha}$ radiation $(\lambda=1.5405 \AA$ ). The Field-emission scanning electron microscopy (FE-SEM) was conducted using a Zeiss SIGMA VP system with gold coating, in order to study the size and morphology of the products. The Fourier transform infrared spectroscopy (FT-IR) spectra, were acquired using a BRUKER EQUINOX 55 spectrophotometer. Furthermore, X-ray photoelectron spectroscopy (XPS) measurement was performed on a Perkin Elmer PHI 6000C ECSA system with monochromatic Al KR (1486.6 eV) irradiation.

\subsection{Electrochemical studies}

Part of the electrochemical measurements were performed on an electrochemical workstation (PGSTAT30, Autolab, Netherland) using three-electrode and two-electrode 
mode in $0.5 \mathrm{M} \mathrm{Na}_{2} \mathrm{SO}_{4}$ aqueous solution. The working electrodes were prepared for the electrochemical tests by preparing a mixture of the produced materials (i.e. pure RGO and $\mathrm{Sm}_{2} \mathrm{O}_{3}$, as well as, $\mathrm{SmN}$-RGO nanocomposites) with acetylene black, and poly(tetrafluoroethylene) at a 80:15:5 mass ratio in ethanol. The resulting uniform paste was then pressed on a current collector, which was a piece of stainless steel, in order to for the electrodes. To this end about $1 \mathrm{mg}$ of the electroactive material and a $1 \mathrm{~cm}^{2}$ current collector were used. Eventually the electrodes were dried in a vacuum oven, at $80^{\circ} \mathrm{C}$ for $4 \mathrm{~h}$. The electrodes manufactured under these conditions shall be referred to as SmRGO throughout the text. The reference and counter electrode were $\mathrm{Ag} / \mathrm{AgCl}$ and platinum electrode, respectively. A three-electrode cell system was used to evaluate the electrochemical performance by electrochemical impedance spectroscopy (EIS), cyclic voltammetry $(\mathrm{CV})$ and the continuous cyclic voltammetry (CCV). A home-made device was used to perform the CCV measurements as described earlier [16, 30, 31].

\section{Table 1.}

\section{Results and discussion}

\subsection{Nanocomposite characterization}

\subsubsection{XRD analysis}

Figure 1 shows the XRD patterns of $\mathrm{GO}, \mathrm{RGO}, \mathrm{Sm}_{2} \mathrm{O}_{3}$ and the $\mathrm{Sm}_{2} \mathrm{O}_{3}-\mathrm{RGO}$ nanocomposites. The most evident peak in the XRD pattern of GO happened at $2 \theta=12.2^{\circ}$, which was attributed to the (001) reflection of graphite oxide [8]. This was not observed in the case of RGO, which is a sign of the complete reduction of GO using hydrazine hydrate [8]. Additionally, the RGO pattern contains two diffraction peaks around $25^{\circ}$ and $43^{\circ}$, which can be attributed to the (002) and (100) planes of the graphite-like structure [12, 21]. The XRD pattern of the $\mathrm{Sm}_{2} \mathrm{O}_{3}$ showed a broadening, which was attributed to the fine dimensions of SmNs, and their low crystallinity. The same pattern was observed for the SmN-RGO nanocomposites, reflecting the presence of the SmNs on the surface of the RGO.

\section{Fig. 1.}

\subsubsection{TEM / FE-SEM studies}


Fig. 2a indicates a layered and winkled morphology for the pure RGO. The FE-SEM image of the SmNs (Fig. 2b) reveals that the nanoparticles are aggregated with a grain size about $20 \mathrm{~nm}$. An almost regular distribution of $\mathrm{SmNs}$ can be seen in the SmN-RGO2 nanocomposite (Fig. 2cd). This confirms the good combination between the RGO and SmNs. The morphology of the SmNs does not change in the pure and composite forms even though the SmNs underwent some aggregation in pure form (Fig. 2b), which implies that the formation of the nanocomposites prevented the agglomeration of the $\mathrm{SmNs}$ and also that the nanoparticles prevent the restacking of the RGO sheets [21].

\section{Fig. 2.}

\subsubsection{FT-IR study}

Fig. 3 illustrates the FT-IR spectra of the GO, $\mathrm{RGO}, \mathrm{Sm}_{2} \mathrm{O}_{3}$ and $\mathrm{SmN}-\mathrm{RGO}$ nanocomposites. The signals at $1735 \mathrm{~cm}^{-1}$ and $1050 \mathrm{~cm}^{-1}$, in the FT-IR spectra of the GO was attributed to the stretching of $\mathrm{C}=\mathrm{O}$ and $\mathrm{C}-\mathrm{OH}$ on $\mathrm{COOH}$ groups. The band at 1621 $\mathrm{cm}^{-1}$ was assigned to the bending vibrations of the surface-adsorbed water molecules as well as the contribution of the $\mathrm{sp}^{2}$ bonds. Also the deformation and stretching vibrations of the $-\mathrm{OH}$ groups were considered as the origin the peaks at around $1397 \mathrm{~cm}^{-1}$ and 3400 $\mathrm{cm}^{-1}$ respectively. Furthermore, a band at $1225 \mathrm{~cm}^{-1}$ is corresponded to the epoxy groups. In the FT-IR spectra of RGO and SmN-RGO nanocomposites, the characteristic absorption band of $\mathrm{GO}$ at $1735 \mathrm{~cm}^{-1}$ is vanished, indicating the successful reduction of GO. Furthermore, these spectra exhibit the characteristic band of graphene around 1585 $\mathrm{cm}^{-1}$.[21] The FT-IR spectrum of $\mathrm{Sm}_{2} \mathrm{O}_{3}$ exhibits a band at $680 \mathrm{~cm}^{-1}$ which has been assigned to a deformation mode of the Sm-O-H of the $\mathrm{Sm}_{2} \mathrm{O}_{3} \cdot \mathrm{xH}_{2} \mathrm{O}$ phase. Furthermore, a shoulder at $1625 \mathrm{~cm}^{-1}$ corresponding to the bending mode of molecular water can be seen in this spectrum [32]. The peak at $1384 \mathrm{~cm}^{-1}$ in the spectra of $\mathrm{Sm}_{2} \mathrm{O}_{3}$ and $\mathrm{SmN}-\mathrm{RGO}$ nanocomposites is assigned to the adsorbed nitrosyl $(\mathrm{N}-\mathrm{O})^{-}$[25]. In the spectra of SmNRGO nanocomposites, the band around $590 \mathrm{~cm}^{-1}$ can be assigned to the $\mathrm{Sm}-\mathrm{O}$ vibration of the strong interaction between $\mathrm{SmNs}$ and RGO which can describe anchoring of nanoparticles on RGO. 


\section{Fig. 3.}

\subsubsection{XPS study}

The SmN-RGO2 nanocomposite is also studied by the X-ray photoelectron (XPS) technique. The wide range XPS survey spectrum of the synthesized sample shown in Fig. 4a indicates no impurities in this nanocomposite. The deconvoluted Sm 3d spectrum (Fig. 4b) consists of two intense bands $1087.3 \mathrm{eV}$ and $1111.4 \mathrm{eV}$ corresponding to $\mathrm{Sm}^{3+}$ and a broad peak with low intensity centered 1099.1 attributed to the $\mathrm{Sm}^{2+}$ component, suggesting a small amount of oxygen vacancy [33]. The O1s spectrum as shown in Fig. 4c was fitted by three components. The weak peak at $534.2 \mathrm{eV}$ may be attributed to the oxygen of $\mathrm{OH}$ groups on the particle surface. The main peak at $531.6 \mathrm{eV}$ could be assigned to the oxygen of $\mathrm{Sm}^{3+}-\mathrm{O}$ groups, and another weaker peak with higher binding energy of $529.3 \mathrm{eV}$ was assigned to the oxygen of $\mathrm{Sm}^{2+}-\mathrm{O}$ groups, which are related to the oxygen in the crystal lattice of $\mathrm{Sm}_{2} \mathrm{O}_{3}$. The coexistence of these peaks reveals the presence of Sm in two different ionic states; therefore, oxygen vacancy in the crystal lattice of $\mathrm{Sm}_{2} \mathrm{O}_{3}$ is helpful for transferring the charge [34]. As shown in Fig. 4d, the curve fitting yields four components at C-C ( $\mathrm{sp}^{2}$ carbon, approximately $284.4 \mathrm{eV}$ ), C-O (hydroxyl and epoxy, approximately $286.5 \mathrm{eV}$ ), and $\mathrm{C}=\mathrm{O}$ (carboxyl, approximately $288.2 \mathrm{eV}$ ), respectively [12, $35]$.

Fig. 4.

\subsection{Electrochemical studies}

\subsubsection{CV and specific capacitances}

The supercapacitive behavior of the RGO, SmN, and SmN-RGO nanocomposite electrodes (i.e. SmRGO1, SmRGO2 and SmRGO3) were monitored using a 3-electrode system and a $0.5 \mathrm{M}$ $\mathrm{Na}_{2} \mathrm{SO}_{4}$ solution as the electrolyte, under ambient. $\mathrm{CV}$ was further used to evaluate the current responses of the materials under the mentioned conditions. The results obtained for the $\mathrm{SmN}$ and SmN-RGO electrodes illustrated by Fig. 5, based on which the corresponding specific capacitance (SC) values were calculated from using the equation below [36];

$S C=\frac{1}{v\left(V_{c}-V_{a}\right)} \int_{V_{a}}^{V_{c}} I d V$ 
where $v$ is the potential scan rate $\left(\mathrm{mV} \mathrm{s}^{-1}\right), \mathrm{V}_{\mathrm{c}}$ and $\mathrm{V}_{\mathrm{a}}$ determine the potential range and I denote the response current $\left(\mathrm{mA} \mathrm{g}^{-1}\right)$ based on the mass of the electroactive material.

\section{Fig. 5.}

Fig. 5a contains the CVs obtained for the RGO, SmN and SmN-RGO electrodes with various ratios in a $0.5 \mathrm{M} \mathrm{Na}_{2} \mathrm{SO}_{4}$ solutions at $50 \mathrm{mVs}^{-1}$. As can be seen in this figure, the rectangular area of the $\mathrm{CV}$ loop in the SmRGO2 is significantly larger than that of $\mathrm{RGO}, \mathrm{SmN}$, SmRGO1 and SmRGO3 electrodes. The SC values of the RGO, SmN, SmRGO1, SmRGO2 and SmRGO3 electrodes were calculated as $76 \mathrm{~F} \mathrm{~g}^{-1}, 87 \mathrm{~F} \mathrm{~g}^{-1}, 180 \mathrm{~F} \mathrm{~g}^{-1}, 227 \mathrm{~F}$

$\mathrm{g}^{-1}$, and $196 \mathrm{~F} \mathrm{~g}^{-1}$ at a scan rate of $50 \mathrm{mV} \mathrm{s}^{-1}$. This can be the result of both the synergistic effects between the components as well as the smaller particles present on the surface of the electrodes. The latter, naturally leads to high specific surface areas, which can in turn enhance the number of active sites available, increasing the amount of energy that supercapacitor electrodes can store [37]. Fig. 5b, 5c, 5d and 5e illustrates the CV curves of the SmN, SmRGO1, SmRGO2 and SmRGO3 at the scan rates of 5, 10, 20, 30, 50, 75 and $100 \mathrm{mV} \mathrm{s}^{-}$ ${ }^{1}$, respectively. All the CVs of the SmRGOs are made of two approximate mirror images with respect to the zero-current line. The fast current response to reversing the voltage at the end of each potential scan proves the ideal pseudo-capacitive nature of the composite. It can be clearly observed that in the case of the SmRGO2, the area of the CVs is significantly larger.

Finally, Fig. 5f illustrates SC vs. scan rate behavior of the $\mathrm{SmN}$ and SmRGOs. It is clear that the SC of SmN and SmN-RGO2 drops from 151 and 321 to 63 and $151 \mathrm{~F} \mathrm{~g}^{-1}$, respectively, as a result of increasing the scan rate. Lower scan rates allow the $\mathrm{Na}^{+}$or $\mathrm{H}^{+}$ ions to thoroughly diffuse into the pores in the electrode material, virtually increasing the surface available for redox reactions, while at higher scan rates this is limited to the outside surface of the electrode material, as a result of which the SC values decrease by increasing the scan rate $[12,16]$.

\subsubsection{CCV}

To evaluate the cycling stability of RGO, SmN, and SmRGOs, CCV analysis were also conducted at $200 \mathrm{mV} \mathrm{s}^{-1}$ for 4000 cycles [16, 31], and the results (Fig. 6) show that among the different SmRGOs, SmRGO2 revealed exceptionally high cyclic stability. The cyclic stability of 
this electrode increased about 5.7\% after 300 cycles and then showed a $1.0 \%$ decrease after 4000 cycles. Similar to SmRGO2 the cyclic stability curve of SmRGO3 first showed a slight increase after 1000 cycles, and finally decreased to $97.6 \%$ of the initial value after 4000 cycles. The initial increase could be the result of the activation of the electrode material, which increases the number of available active sites.

In the case of the RGO, SmN, and SmRGO1 electrodes the cyclic stability decreased by 3.9\%, $23.6 \%$ and $4.2 \%$ after 4000 cycles. The results indicate that the RGO content of the electrodes considerably influences the cyclic stability of the electrodes, and hence the application of the optimal amounts of RGO is crucial for improved cyclic stability. Further it is evident that the considerable stability of RGO-based electrodes, even at high scan rates makes them a suitable candidate for applications requiring fast charging. Fig. $6 b, 6 c$ and $6 \mathrm{~d}$ illustrates threedimensional (3D) CCVs, which was performed at a scan rate of $200 \mathrm{mV} \mathrm{s}^{-1}$. In these three 3Dplots, the changes in the CVs over number of cycles are more noticeable.

\section{Fig. 6.}

\subsubsection{Charge/discharge}

Galvanostatic charge/discharge analyses were also conducted to evaluate the supercapacitive performance of the electrodes. For this purpose, a two-electrode system was used. Fig. 7a illustrates the charge/discharge curves of the RGO, SmN, and SmRGO electrodes at the current density of $2.0 \mathrm{Ag}^{-1}$. The results reveal that the curves of SmRGOs to be triangular, linear, symmetric and very sharp. Equal charge/discharge durations for each electrode indicate

reversible behavior, high columbic efficiency, and an ideal capacitor performance. The SC values were also calculated using the charge/discharge data by means of the following equation:

$$
S C=\frac{I \Delta t}{\Delta V}
$$

where $I$ is the charge/discharge current (A), $\Delta t$ is the discharge time (s), and $\mathrm{V}$ is the potential drop during discharge (V).

Fig. 7. 
In the case of the SmRGO2 a specific capacitance of $268 \mathrm{Fg}^{-1}$ was achieved at $2 \mathrm{Ag}^{-1}$, which further proved to be the largest value among all the electrodes. Fig. $7 \mathrm{~b}$ illustrates the charge/discharge curves of this electrode in the -0.8 to $0.2 \mathrm{~V}$ window at various current densities from 2 to $32 \mathrm{~A} \mathrm{~g}^{-1}$. The equilateral triangular curves in all cases indicate the ideal capacitive behavior and reversibility of the material in the charge/discharge processes, which was attributed to the considerable electrical conductivity of RGO (due to the presence of $\mathrm{SmN}$ ), and the rapid redox reactions stemming from the facilitated charge transport from $\mathrm{Sm}_{2} \mathrm{O}_{3}$ as a function of uniform distribution of $\mathrm{SmN}$ on the RGO sheets [38].

According to the results acquired from $\mathrm{CV}$, charge/discharge and $\mathrm{CCV}$, supercapacitive performance of SmRGO2 electrode is much better compared to the other works presented in Table 2. As can be seen in Table 2, the maximum SC and stability of SmRGO2 electrode are higher than those of graphene/metal oxide composites that have been investigated in aqueous electrolytes so far.

\section{Table 2.}

The superior performance of the SmRGO2, in comparison with the other electrodes was also verified by the Ragone plot as shown in Fig. 7c. The energy and power densities, required for this plot, were acquired from charge/discharge analysis at the various current densities and the highest energy density (i.e. $38.1 \mathrm{~W} \mathrm{~h} \mathrm{Kg}^{-1}$ ) was observed for the SmRGO2 at the power density

of $500 \mathrm{~W} \mathrm{Kg}^{-1}$. The value was found to be considerably higher than those reported for the same electrode in the literature [44-46]. Upon increasing power density, the energy density values of this electrode decreased lower sharply than the other composite electrodes, indicating the higher available active sites in SmRGO2. Based on the energy and power densities the SmN-RGO composites were considered as suitable materials for supercapacitor electrodes.

\subsubsection{EIS studies}

To compare the internal resistance of the electrode materials with the external resistance between the electrode and electrolyte, EIS evaluations were also conducted. The EIS measurements of SmRGOs were performed at open circuit potential (OCP) in the range of $0.1-10^{5} \mathrm{~Hz}$ (Fig. 8). The charge transfer between electrode and electrolyte leads to semicircular patterns in the 
Nyquist plot at the high frequency region. This is followed by a tail caused by the diffusion of the ions into the electrode, at lower frequencies. Alternatively, it can be said that the electrochemical reaction impedance influences the size of semicircle, in a way that smaller semicircle radius translates to smaller charge transfer resistance [47]. The EIS curves were analyzed through complex nonlinear least square (CNLS) fitting method [48], for an equivalent circuit according to Fig. 8 (inset), which can be seen as the combination of five elements of $R_{\mathrm{s}}$, $R_{\mathrm{ct}}, C_{\mathrm{dl}}, Z_{\mathrm{W}}$, and $C_{\mathrm{F}}$. $\left(R_{\mathrm{s}}\right.$ : the internal resistance, the sum of the intrinsic resistance of the active material, resistance of the bulk electrolyte, and the ionic resistance of the electrolyte at current collector/electrode interface [49]; $Z_{W}$ : Warburg resistance, indicating the frequency dependence of ion diffusion/transport to the surface of the electrode [50]; $R_{\mathrm{ct}}:$ the electrode/electrolyte interfacial charge transfer resistance; $C_{\mathrm{dl}}$ : the electrical double layer capacitance at the electrode/electrolyte interface; and $C_{\mathrm{F}}$ : pseudo-capacitance of the faradic reaction).

The values obtained for the equivalent circuit are given in Table 3, which shows that $R_{\text {ct }}$ of SmRGO2 is less than those of the other composite electrodes. Low $R_{c t}$ indicates that the electrochemical reaction is more facile at the electrode/electrolyte interfaces. Similarly, as seen in Table 3, the SmRGO2 was concluded as being superior, in terms of the electrochemical performance, to the other composite electrodes. The highest values of electrical double layer capacitance $\left(C_{d l}\right)$ and faradic pseudocapacitor $\left(C_{F}\right)$ are corresponded to the SmRGO2. Also, SmRGO2, further proved to have a more ideal Warburg resistance (the closeness of the line to verticality is indication of the fact that the electrode is closer to an ideal capacitor) [51]. The EIS actually revealed that the synergy between the SmN and RGO sheets reached its peak at the composition of the SmRGO2, which was further approved by CVs and chronopotentiograms.

Fig. 8.

Table 3.

\section{Conclusion}

Samarium oxide/RGO nanocomposites, were prepared through a simple sonochemical procedure, and the evaluation showed that the presence of RGO led to improved conductivity by declining the ionic mass-transfer resistance. Experiments revealed that SmN-RGO nanocomposite 
electrodes reveal better behaviors as opposed to those based on pure RGO or $\mathrm{Sm}_{2} \mathrm{O}_{3}$ in terms of $\mathrm{SC}$, stability, and energy density. It was also concluded that a composition of $1: 1 \mathrm{wt}$ of $\mathrm{Sm}_{2} \mathrm{O}_{3}$ to RGO (referred to as SmN-RGO2) leads to the best supercapacitive performance, with an SC of approximately $321 \mathrm{~F} \mathrm{~g}^{-1}$, at a scan rate of $2 \mathrm{mV} \mathrm{s}^{-1}$, which is much enhanced with respect to pure RGO and $\mathrm{Sm}_{2} \mathrm{O}_{3}$ electrodes. The stability of the nanocomposite electrodes was assessed by $\mathrm{CCV}$, at $200 \mathrm{mVs}^{-1}$, which indicated that the $\mathrm{SC}$ of the $\mathrm{SmN}-\mathrm{RGO} 2$ based electrodes remained at approximately $99.0 \%$ of its initial value, after 4000 cycles. EIS and galvanostatic charge/discharge evaluations confirmed these findings and hence, the optimal SmN-RGO nanocomposites were suggested as a promising candidate for use in the construction of high performance super-capacitor electrodes. The proposed synthesis, also seems to be extendable to other metal oxides and carbonaceous materials such as CNTs and mesoporous carbon, which can be used in super-capacitor technologies.

\section{Acknowledgements}

The financial support of this work by Iran National Science Foundation (INSF) and University of Tehran is gratefully acknowledgments.

\section{References}

[1] G. Lee, Y. Cheng, C.V. Varanasi, J. Liu, Influence of the Nickel Oxide Nanostructure Morphology on the Effectiveness of Reduced Graphene Oxide Coating in Supercapacitor Electrodes, The Journal of Physical Chemistry C, 118 (2014) 2281-2286.

[2] Z.-S. Wu, G. Zhou, L.-C. Yin, W. Ren, F. Li, H.-M. Cheng, Graphene/metal oxide composite electrode materials for energy storage, Nano Energy, 1 (2012) 107-131.

[3] Y. Wang, C.X. Guo, J. Liu, T. Chen, H. Yang, C.M. Li, CeO2 nanoparticles/graphene nanocompositebased high performance supercapacitor, Dalton transactions, 40 (2011) 6388-6391.

[4] H.R. Naderi, H.R. Mortaheb, A. Zolfaghari, Supercapacitive properties of nanostructured $\mathrm{MnO2}$ /exfoliated graphite synthesized by ultrasonic vibration, Journal of Electroanalytical Chemistry, 719 (2014) 98-105.

[5] A.G. Pandolfo, A.F. Hollenkamp, Carbon properties and their role in supercapacitors, Journal of Power Sources, 157 (2006) 11-27.

[6] G. Wang, L. Zhang, J. Zhang, A review of electrode materials for electrochemical supercapacitors, Chemical Society reviews, 41 (2012) 797-828.

[7] D. Joung, V. Singh, S. Park, A. Schulte, S. Seal, S.I. Khondaker, Anchoring Ceria Nanoparticles on Reduced Graphene Oxide and Their Electronic Transport Properties, Journal of Physical Chemistry C, 115 (2011) 24494-24500. 
[8] L.H. Jiang, M.G. Yao, B. Liu, Q.J. Li, R. Liu, H. Lv, S.C. Lu, C. Gong, B. Zou, T. Cui, B.B. Liu, G.Z. Hu, T. Wagberg, Controlled Synthesis of $\mathrm{CeO} 2 /$ Graphene Nanocomposites with Highly Enhanced Optical and Catalytic Properties, Journal of Physical Chemistry C, 116 (2012) 11741-11745.

[9] S.P. Yu, Q.B. Liu, W.S. Yang, K.F. Han, Z.M. Wang, H. Zhu, Graphene-CeO2 hybrid support for Pt nanoparticles as potential electrocatalyst for direct methanol fuel cells, Electrochimica Acta, 94 (2013) 245-251.

[10] H. Teymourian, A. Salimi, S. Khezrian, Fe3O4 magnetic nanoparticles/reduced graphene oxide nanosheets as a novel electrochemical and bioeletrochemical sensing platform, Biosens Bioelectron, 49 (2013) 1-8.

[11] Z. Ji, X. Shen, M. Li, H. Zhou, G. Zhu, K. Chen, Synthesis of reduced graphene oxide/CeO2 nanocomposites and their photocatalytic properties, Nanotechnology, 24 (2013) 115603.

[12] H.R. Naderi, M.R. Ganjali, A.S. Dezfuli, P. Norouzi, Sonochemical preparation of a ytterbium oxide/reduced graphene oxide nanocomposite for supercapacitors with enhanced capacitive performance, RSC Advances, 6 (2016) 51211-51220.

[13] C. Yang, L. Zhang, N. Hu, Z. Yang, H. Wei, Z.J. Xu, Y. Wang, Y. Zhang, Densely-packed graphene/conducting polymer nanoparticle papers for high-volumetric-performance flexible all-solidstate supercapacitors, Applied Surface Science, 379 (2016) 206-212.

[14] C. Yang, L. Zhang, N. Hu, Z. Yang, H. Wei, Y. Wang, Y. Zhang, High-performance flexible all-solid-state supercapacitors based on densely-packed graphene/polypyrrole nanoparticle papers, Applied Surface Science, 387 (2016) 666-673.

[15] N. Hu, L. Zhang, C. Yang, J. Zhao, Z. Yang, H. Wei, H. Liao, Z. Feng, A. Fisher, Y. Zhang, Threedimensional skeleton networks of graphene wrapped polyaniline nanofibers: an excellent structure for high-performance flexible solid-state supercapacitors, Scientific reports, 6 (2016).

[16] A.S. Dezfuli, M.R. Ganjali, H.R. Naderi, P. Norouzi, A high performance supercapacitor based on a ceria/graphene nanocomposite synthesized by a facile sonochemical method, RSC Advances, 5 (2015) 46050-46058.

[17] R.B. Rakhi, W. Chen, D. Cha, H.N. Alshareef, High performance supercapacitors using metal oxide anchored graphene nanosheet electrodes, Journal of Materials Chemistry, 21 (2011) 16197.

[18] Q. Liao, N. Li, S. Jin, G. Yang, C. Wang, All-Solid-State Symmetric Supercapacitor Based on Co3O4 Nanoparticles on Vertically Aligned Graphene, ACS nano, (2015).

[19] W. He, J. Lin, B. Wang, S. Tuo, S.T. Pantelides, J.H. Dickerson, An analytical expression for the van der Waals interaction in oriented-attachment growth: a spherical nanoparticle and a growing cylindrical nanorod, Phys Chem Chem Phys, (2012).

[20] B. Wang, J. Park, C. Wang, H. Ahn, G. Wang, Mn3O4 nanoparticles embedded into graphene nanosheets: Preparation, characterization, and electrochemical properties for supercapacitors, Electrochimica Acta, 55 (2010) 6812-6817.

[21] A.S. Dezfuli, M.R. Ganjali, P. Norouzi, F. Faridbod, Facile sonochemical synthesis and electrochemical investigation of ceria/graphene nanocomposites, Journal of Materials Chemistry B, 3 (2015) 2362-2370.

[22] G.-y. Adachi, N. Imanaka, Z.C. Kang, Binary Rare Earth Oxides, Springer Netherlands, 2004.

[23] M.P. Rosynek, Catalytic Properties of Rare Earth Oxides, Catalysis Reviews, 16 (1977) 111-154.

[24] J.-H. Jhang, A. Schaefer, W. Cartas, S. Epuri, M. Bäumer, J.F. Weaver, Growth and Partial Reduction of Sm2O3(111) Thin Films on Pt(111): Evidence for the Formation of SmO(100), The Journal of Physical Chemistry C, 117 (2013) 21396-21406.

[25] S. Tsujimoto, T. Masui, N. Imanaka, Fundamental Aspects of Rare Earth Oxides Affecting Direct NO Decomposition Catalysis, European Journal of Inorganic Chemistry, 2015 (2015) 1524-1528.

[26] E. Antolini, J. Perez, The use of rare earth-based materials in low-temperature fuel cells, International Journal of Hydrogen Energy, 36 (2011) 15752-15765. 
[27] D.A. Johnson, Principles of lanthanide chemistry, Journal of Chemical Education, 57 (1980) 475.

[28] D.A. Atwood, The Rare Earth Elements: Fundamentals and Applications, John Wiley and Sons, 2012.

[29] D.C. Marcano, D.V. Kosynkin, J.M. Berlin, A. Sinitskii, Z.Z. Sun, A. Slesarev, L.B. Alemany, W. Lu, J.M.

Tour, Improved Synthesis of Graphene Oxide, ACS nano, 4 (2010) 4806-4814.

[30] P. Norouzi, B. Larijani, M. Ezoddin, M.R. Ganjali, Sub-second adsorption for the fast sub-nanomolar monitoring of Clindamycin in its pure and pharmaceutical samples by fast Fourier transformation with the use of continuous cyclic voltammetry at an Au microelectrode in a flowing system, Materials Science and Engineering: C, 28 (2008) 87-93.

[31] P. Norouzi, T.M. Garakani, M.R. Ganjali, Using fast Fourier transformation continuous cyclic voltammetry method for new electrodeposition of nano-structured lead dioxide, Electrochimica Acta, 77 (2012) 97-103.

[32] S. Bernal, F.J. Botana, R. García, J.M. Rodríguez-Izquierdo, Behaviour of rare earth sesquioxides exposed to atmospheric carbon dioxide and water, Reactivity of Solids, 4 (1987) 23-40.

[33] T.-D. Nguyen, D. Mrabet, T.-O. Do, Controlled Self-Assembly of Sm2O3 Nanoparticles into Nanorods: Simple and Large Scale Synthesis using Bulk Sm2O3 Powders, The Journal of Physical Chemistry C, 112 (2008) 15226-15235.

[34] J. Singh, A. Roychoudhury, M. Srivastava, P.R. Solanki, D.W. Lee, S.H. Lee, B.D. Malhotra, A highly efficient rare earth metal oxide nanorods based platform for aflatoxin detection, Journal of Materials Chemistry B, 1 (2013) 4493-4503.

[35] H.R. Naderi, P. Norouzi, M.R. Ganjali, H. Gholipour-Ranjbar, Synthesis of a novel magnetite/nitrogen-doped reduced graphene oxide nanocomposite as high performance supercapacitor, Powder Technology, 302 (2016) 298-308.

[36] S. Devaraj, N. Munichandraiah, High capacitance of electrodeposited $\mathrm{MnO} 2$ by the effect of a surface-active agent, Electrochemical and Solid-State Letters, 8 (2005) A373-A377.

[37] Y.-j. Yang, E.-H. Liu, L.-m. Li, Z.-z. Huang, H.-j. Shen, X.-x. Xiang, Nanostructured MnO 2/exfoliated graphite composite electrode as supercapacitors, Journal of Alloys and Compounds, 487 (2009) 564-567. [38] H.-J. Choi, S.-M. Jung, J.-M. Seo, D.W. Chang, L. Dai, J.-B. Baek, Graphene for energy conversion and storage in fuel cells and supercapacitors, Nano Energy, 1 (2012) 534-551.

[39] H.-W. Wang, Z.-A. Hu, Y.-Q. Chang, Y.-L. Chen, Z.-Y. Zhang, Y.-Y. Yang, H.-Y. Wu, Preparation of reduced graphene oxide/cobalt oxide composites and their enhanced capacitive behaviors by homogeneous incorporation of reduced graphene oxide sheets in cobalt oxide matrix, Materials Chemistry and Physics, 130 (2011) 672-679.

[40] H. Gholipour-Ranjbar, M.R. Ganjali, P. Norouzi, H.R. Naderi, Synthesis of cross-linked graphene aerogel/Fe 203 nanocomposite with enhanced supercapacitive performance, Ceramics International, (2016).

[41] Y. Bu, S. Wang, H. Jin, W. Zhang, J. Lin, J. Wang, Synthesis of porous NiO/reduced graphene oxide composites for supercapacitors, Journal of The Electrochemical Society, 159 (2012) A990-A994.

[42] H. Gholipour-Ranjbar, M.R. Ganjali, P. Norouzi, H.R. Naderi, Functionalized graphene aerogel with pphenylenediamine and its composite with porous $\mathrm{MnO} 2$ : investigating the effect of functionalizing agent on supercapacitive performance, Journal of Materials Science: Materials in Electronics, 27 (2016) 1016310172.

[43] Ü. Alver, A. Tanrıverdi, Boron doped $\mathrm{ZnO}$ embedded into reduced graphene oxide for electrochemical supercapacitors, Applied Surface Science, 378 (2016) 368-374.

[44] B. Li, Y. Fu, H. Xia, X. Wang, High-performance asymmetric supercapacitors based on MnFe 20 4/graphene nanocomposite as anode material, Materials Letters, 122 (2014) 193-196.

[45] X. Zhang, X. Sun, H. Zhang, D. Zhang, Y. Ma, Development of redox deposition of birnessite-type $\mathrm{MnO} 2$ on activated carbon as high-performance electrode for hybrid supercapacitors, Materials Chemistry and Physics, 137 (2012) 290-296. 
[46] G. Yu, L. Hu, M. Vosgueritchian, H. Wang, X. Xie, J.R. McDonough, X. Cui, Y. Cui, Z. Bao, Solutionprocessed graphene/MnO2 nanostructured textiles for high-performance electrochemical capacitors, Nano letters, 11 (2011) 2905-2911.

[47] L.-F. Chen, X.-D. Zhang, H.-W. Liang, M. Kong, Q.-F. Guan, P. Chen, Z.-Y. Wu, S.-H. Yu, Synthesis of nitrogen-doped porous carbon nanofibers as an efficient electrode material for supercapacitors, ACS nano, 6 (2012) 7092-7102.

[48] B.E. Conway, Electrochemical Supercapacitors, 1 ed., Springer US, 1999.

[49] A. Zolfaghari, H.R. Naderi, H.R. Mortaheb, Carbon black/manganese dioxide composites synthesized by sonochemistry method for electrochemical supercapacitors, Journal of Electroanalytical Chemistry, 697 (2013) 60-67.

[50] K. Zhang, L.L. Zhang, X. Zhao, J. Wu, Graphene/polyaniline nanofiber composites as supercapacitor electrodes, Chemistry of Materials, 22 (2010) 1392-1401.

[51] L. Li, K.H. Seng, H. Liu, I.P. Nevirkovets, Z. Guo, Synthesis of Mn 30 4-anchored graphene sheet nanocomposites via a facile, fast microwave hydrothermal method and their supercapacitive behavior, Electrochimica Acta, 87 (2013) 801-808. 
Table 1. Theoretical $\mathrm{Sm}_{2} \mathrm{O}_{3} / \mathrm{RGO}$ ratios in various $\mathrm{SmN}-\mathrm{RGO}$ compositions applied in related electrodes.

\begin{tabular}{cccc}
\hline Electrode & Nanocomposite & $\mathrm{Sm}^{3+}(\mathrm{mmol})$ & $\begin{array}{c}\text { Theoretical mass } \\
\text { ratio } \mathrm{Sm}_{2} \mathrm{O}_{3} / \mathrm{GO}\end{array}$ \\
\hline SmRGO1 & SmN-RGO1 & 0.35 & $2 / 1$ \\
SmRGO2 & SmN-RGO2 & 0.175 & $1 / 1$ \\
SmRGO3 & SmN-RGO3 & 0.0875 & $1 / 2$ \\
\hline
\end{tabular}


Table 2. Comparison between supercapacitive behavior of $\mathrm{Sm}_{2} \mathrm{O}_{3} / \mathrm{RGO}$ and some reported metal oxide/graphene composite electrodes.

\begin{tabular}{|c|c|c|c|c|c|}
\hline Composite & Electrolyte & $\begin{array}{c}\text { Potential } \\
\text { window }(\mathrm{V})\end{array}$ & Specific capacitance & Cycling stability & Ref. \\
\hline $\mathrm{Yb}_{2} \mathrm{O}_{3} / \mathrm{RGO}$ & $0.5 \mathrm{M} \mathrm{Na}_{2} \mathrm{SO}_{4}$ & $-0.9-0.1$ & $240 \mathrm{Fg}^{-1}\left(2 \mathrm{mV} \mathrm{s}^{-1}\right)$ & $96.5 \%$ (4000 cycles) & {$[12]$} \\
\hline $\mathrm{CeO}_{2} / \mathrm{RGO}$ & $0.5 \mathrm{M} \mathrm{Na}_{2} \mathrm{SO}_{4}$ & $-0.8-0.6$ & $211 \mathrm{Fg}^{-1}\left(5 \mathrm{mV} \mathrm{s}^{-1}\right)$ & $105.6 \%$ (4000 cycles) & [16] \\
\hline $\mathrm{Fe}_{3} \mathrm{O}_{4} / \mathrm{RGO}$ & $0.5 \mathrm{M} \mathrm{Na}_{2} \mathrm{SO}_{4}$ & $-0.8-0.2$ & $271 \mathrm{Fg}^{-1}\left(2 \mathrm{mV} \mathrm{s}^{-1}\right)$ & $93.8 \%$ (4000 cycles) & {$[35]$} \\
\hline $\mathrm{Co}_{3} \mathrm{O}_{4} / \mathrm{RGO}$ & $6.0 \mathrm{M} \mathrm{KOH}$ & $-0.6-0.55$ & $291 \mathrm{Fg}^{-1}\left(1 \mathrm{~A} \mathrm{~g}^{-1}\right)$ & $90.0 \%$ (1000 cycles) & [39] \\
\hline $\mathrm{Fe}_{2} \mathrm{O}_{3} / \mathrm{RGO}$ & $3.0 \mathrm{M} \mathrm{KOH}$ & $-1.0-0.0$ & $300 \mathrm{Fg}^{-1}\left(5 \mathrm{mV} \mathrm{s}^{-1}\right)$ & $75.0 \%$ (5000 cycles) & [40] \\
\hline $\mathrm{NiO} / \mathrm{RGO}$ & $6.0 \mathrm{M} \mathrm{KOH}$ & $-0.4-0.5$ & $461 \mathrm{Fg}^{-1}\left(0.2 \mathrm{~A} \mathrm{~g}^{-1}\right)$ & $74.5 \%$ (5000 cycles) & [41] \\
\hline $\mathrm{MnO}_{2} / \mathrm{RGO}$ & $0.5 \mathrm{M} \mathrm{Na}_{2} \mathrm{SO}_{4}$ & $-1.0-0.8$ & $265 \mathrm{Fg}^{-1}\left(1 \mathrm{Ag}^{-1}\right)$ & $93.8 \%$ (4000 cycles) & [42] \\
\hline $\mathrm{ZnO} / \mathrm{RGO}$ & $6.0 \mathrm{M} \mathrm{KOH}$ & $-0.6-0.6$ & $230 \mathrm{Fg}^{-1}\left(5 \mathrm{mV} \mathrm{s}^{-1}\right)$ & $89.8 \%$ (100 cycles) & {$[43]$} \\
\hline $\mathrm{Sm}_{2} \mathrm{O}_{3} / \mathrm{RGO}$ & $0.5 \mathrm{M} \mathrm{Na}_{2} \mathrm{SO}_{4}$ & $-0.8-0.2$ & $321 \mathrm{Fg}^{-1}\left(2 \mathrm{mV} \mathrm{s}^{-1}\right)$ & $99.0 \%$ (4000 cycles) & $\begin{array}{l}\text { This } \\
\text { Work }\end{array}$ \\
\hline
\end{tabular}


Table 3. $\mathrm{R}_{\mathrm{s}}, \mathrm{C}_{\mathrm{dl}}, \mathrm{R}_{\mathrm{ct}}, \mathrm{Z}_{\mathrm{w}}$, and $\mathrm{C}_{\mathrm{F}}$ values calculated through CNLS fitting of the experimental impedance spectra for the given equivalent circuit.

\begin{tabular}{cccc}
\hline & SmRGO1 & SmRGO2 & SmRGO3 \\
\hline $\mathrm{R}_{\mathrm{s}}(\mathrm{Ohm})$ & 1.22 & 1.09 & 1.22 \\
$\mathrm{C}_{\mathrm{dl}}(\mathrm{mF})$ & 1.02 & 1.1 & 0.79 \\
$\mathrm{Z}_{\mathrm{W}}$ & 0.18 & 0.21 & 0.16 \\
$\mathrm{R}_{\mathrm{ct}}(\mathrm{Ohm})$ & 3.11 & 1.83 & 2.16 \\
$\mathrm{C}_{\mathrm{F}}(\mathrm{mF})$ & 218 & 341 & 290 \\
\hline
\end{tabular}




\section{Figures Legend}

Scheme 1. Schematic presentation of procedure for the synthesis of SmN-RGO nanocomposite.

Fig. 1. X-ray diffraction patterns of $\mathrm{RGO}, \mathrm{Sm}_{2} \mathrm{O}_{3}$, and $\mathrm{SmN}-\mathrm{RGO}$ nanocomposites.

Fig. 2. a and b) FE-SEM images of RGO and $\mathrm{Sm}_{2} \mathrm{O}_{3}$, c and d) TEM and FE-SEM images of $\mathrm{SmN}-\mathrm{RGO} 2$.

Fig. 3. FT-IR spectra of GO, $\mathrm{RGO}, \mathrm{Sm}_{2} \mathrm{O}_{3}$ and $\mathrm{SmN}-\mathrm{RGO}$ nanocomposites.

Fig. 4. XPS spectra of SmN-RGO2 nanocomposite.

Fig. 5. (a) The cyclic voltammograms of the $\mathrm{SmN}$ and $\mathrm{SmN}-\mathrm{RGO}$ electrodes with various ratios at $50 \mathrm{mV} \mathrm{s}^{-1}$, (b) $\mathrm{CVs}$ of the SmN-RGO electrodes containing various amounts of RGO (at 50 $\mathrm{mV} \mathrm{s}^{-1}$ ), (c) CVs of an SmN-RGO electrode at various scan rates in the range of 10-200 mV s${ }^{-1}$ ), and (d) Changes in the SC values vs. the scan rate.

Fig. 6. (a) Changes in the specific capacitance of the RGO, SmN and different SmRGOs as a function of number of cycles, at $200 \mathrm{mV} \mathrm{s}^{-1}$. 3D-CCV curves obtained at $200 \mathrm{mV} \mathrm{s}^{-1}$ for (b) RGO, (c) SmN and (d) SmRGO2 electrode.

Fig. 7. (a) Charge/discharge curves of RGO, SmN and different SmRGOs at a charge/discharge current density of $2.0 \mathrm{~A} \mathrm{~g} \mathrm{~g}^{-1}$, (b) charge/discharge curves of the SmRGO2 at various current densities in the range of 2-32 $\mathrm{Ag}^{-1}$, (c) the Ragone (power density vs. energy density) plot of the SmN and SmRGOs with different compositions (The energy and power density data were derived from the charge/discharge curves at various current densities).

Fig. 8. Nyquist plots of the impedance spectra of different SmRGOs at OCP in the range of $0.1-10^{5} \mathrm{~Hz}$. 


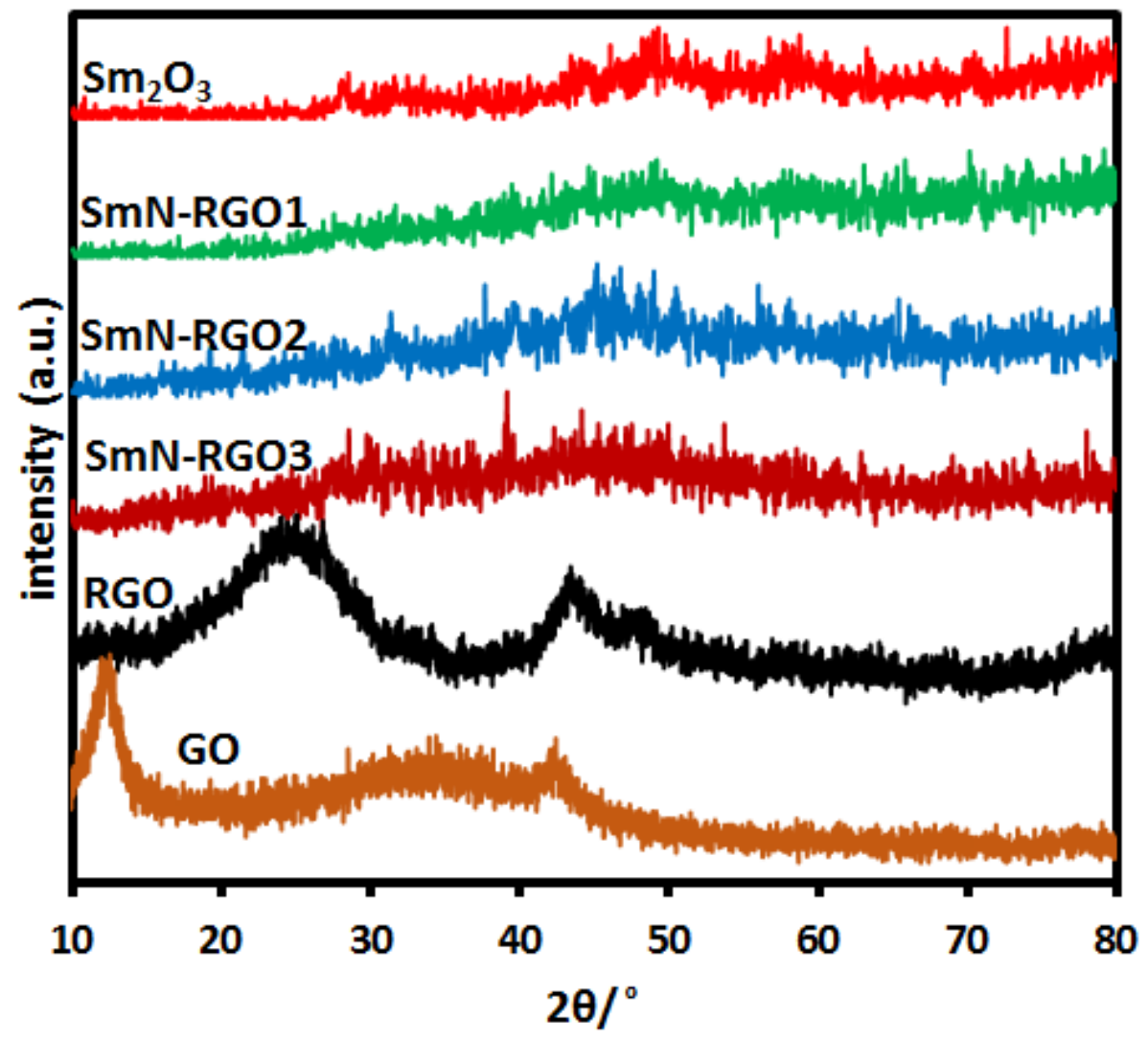

Fig. 1 


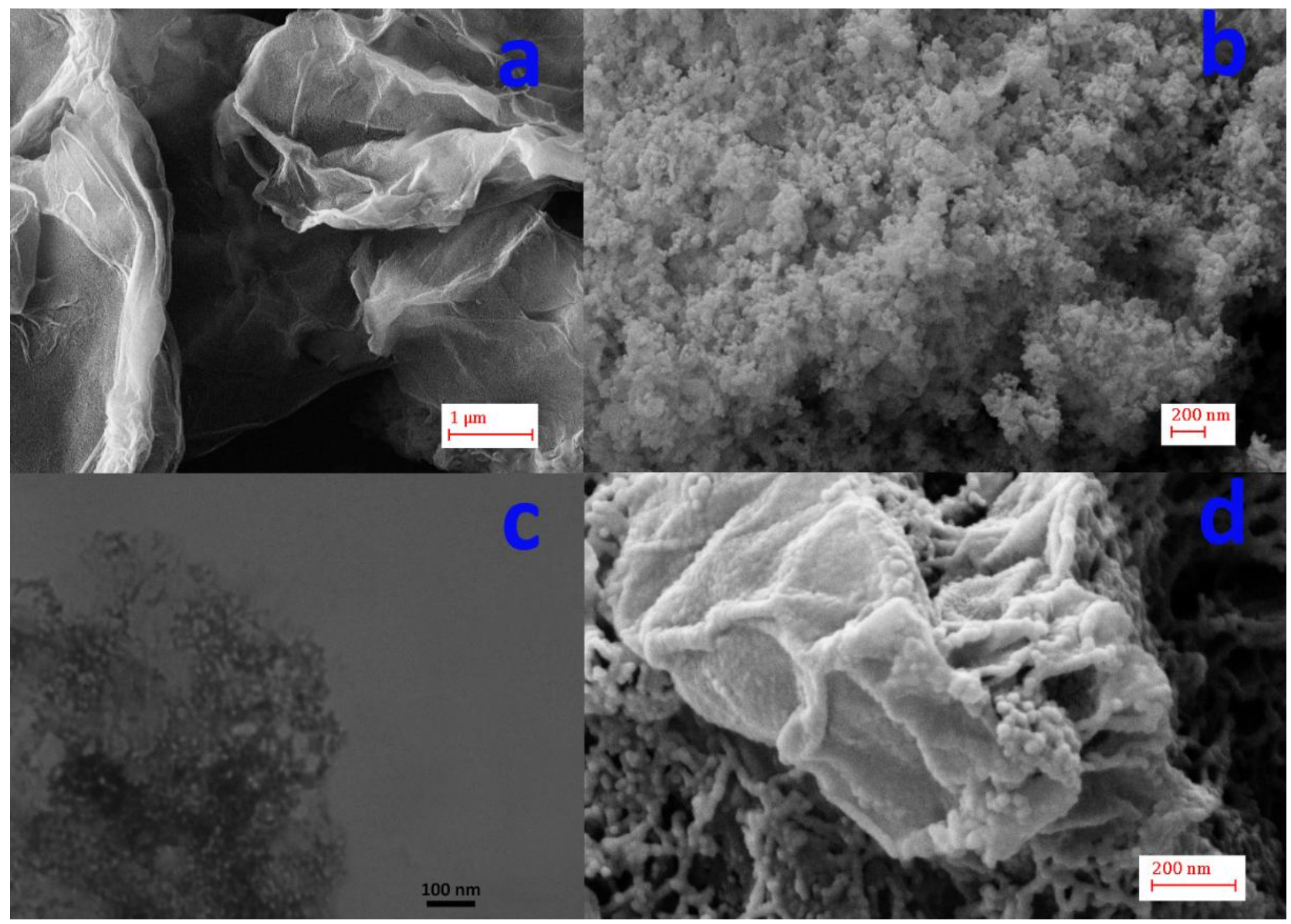

Fig. 2 


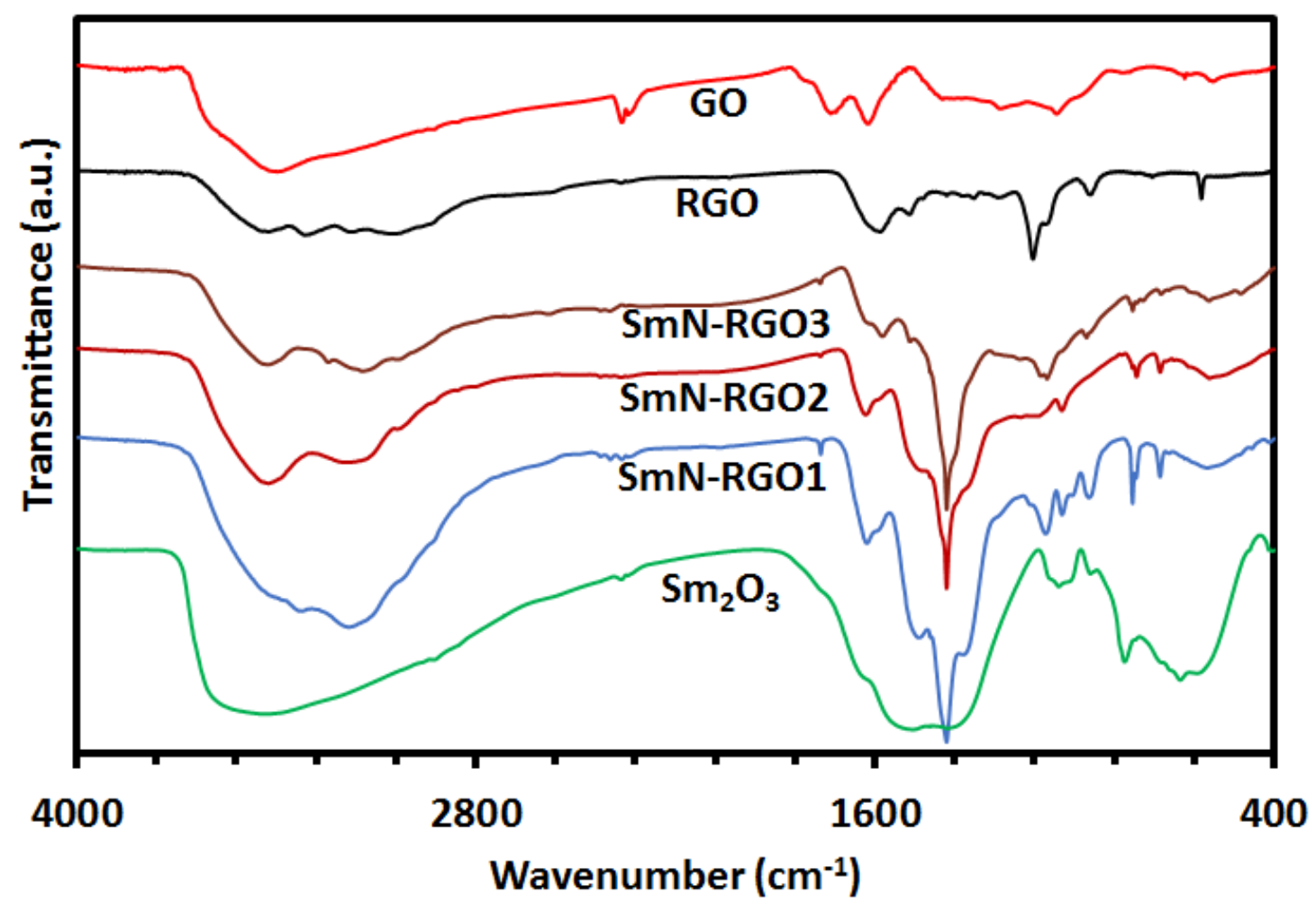

Fig. 3 

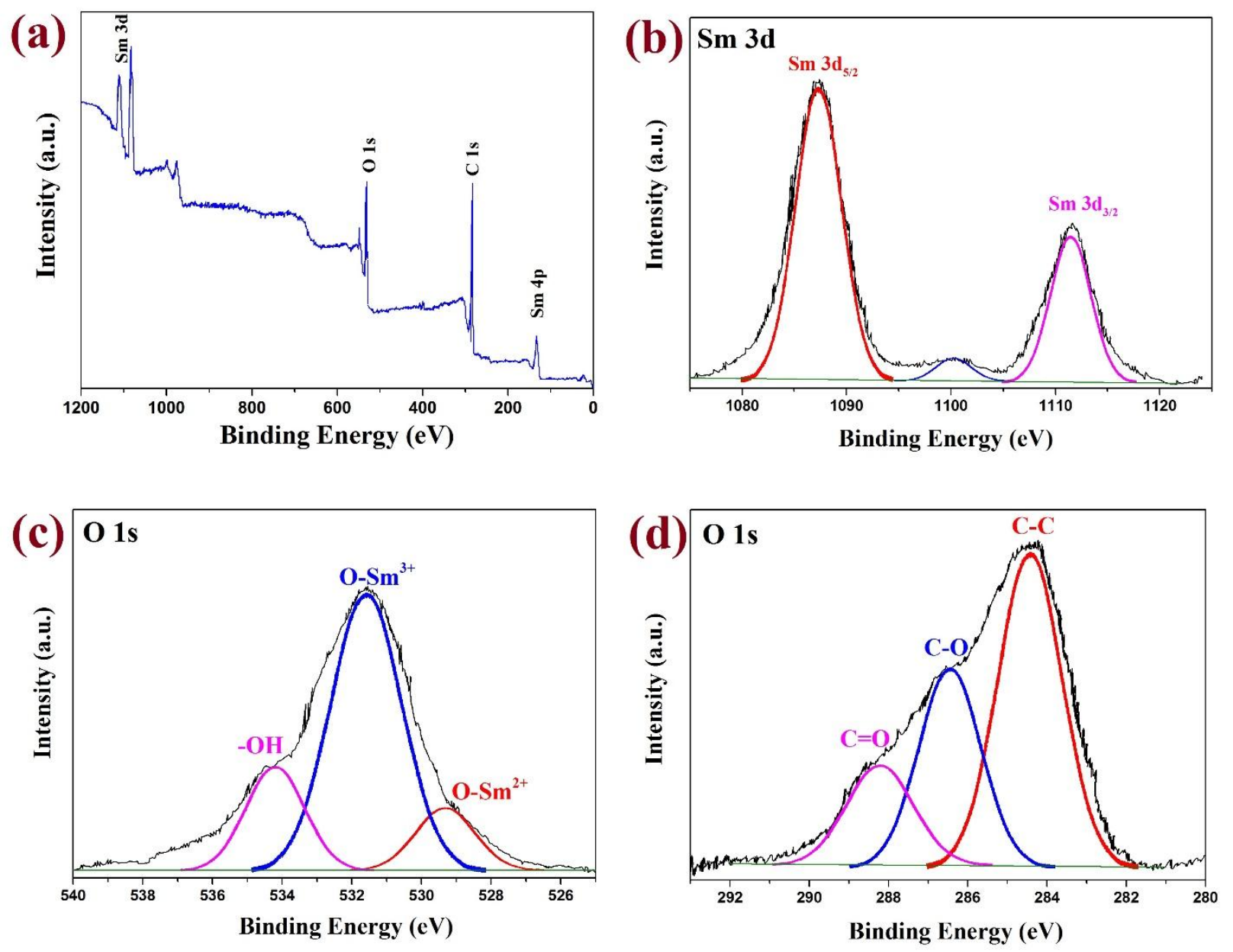

Fig. 4 

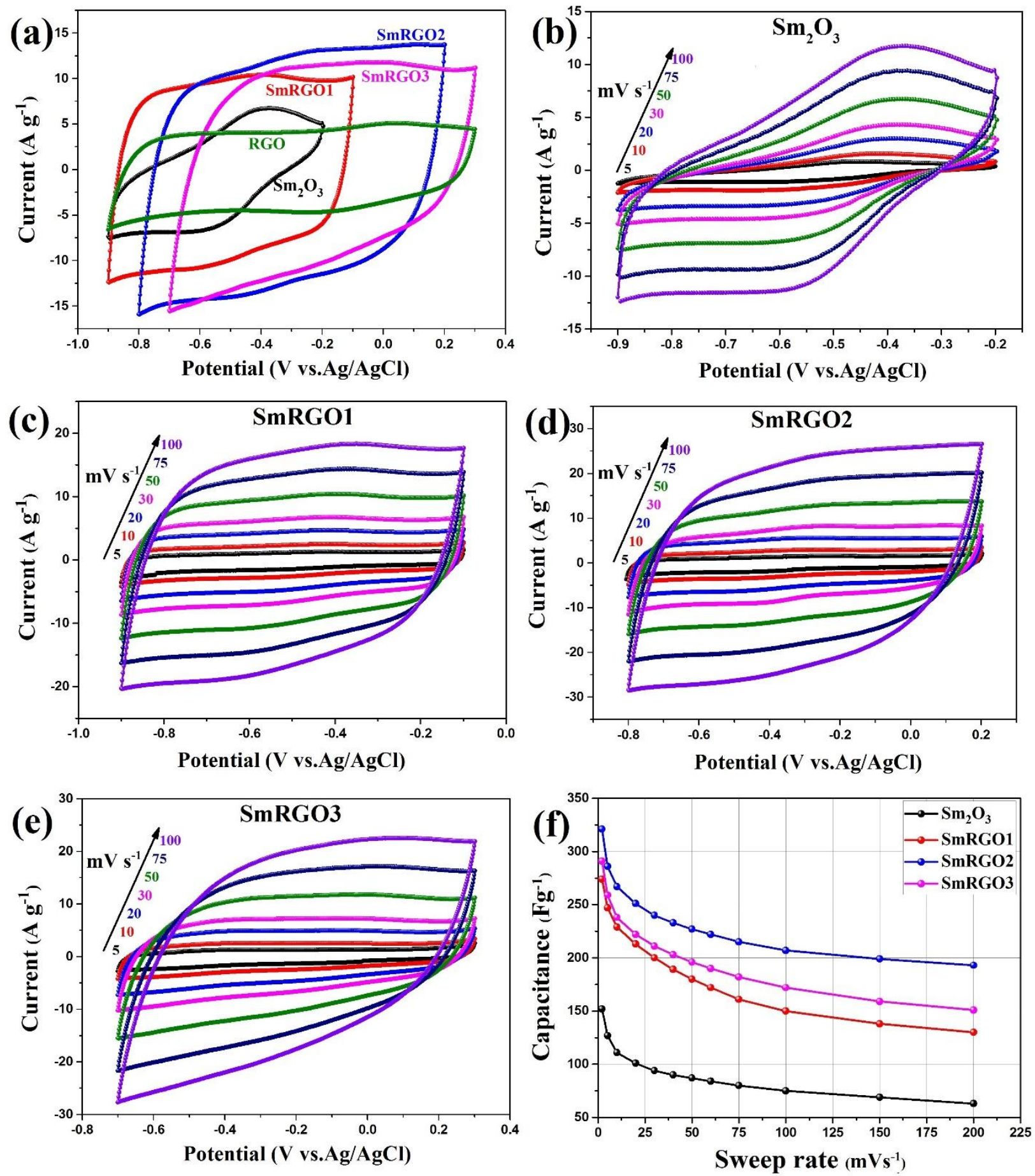

Fig. 5 

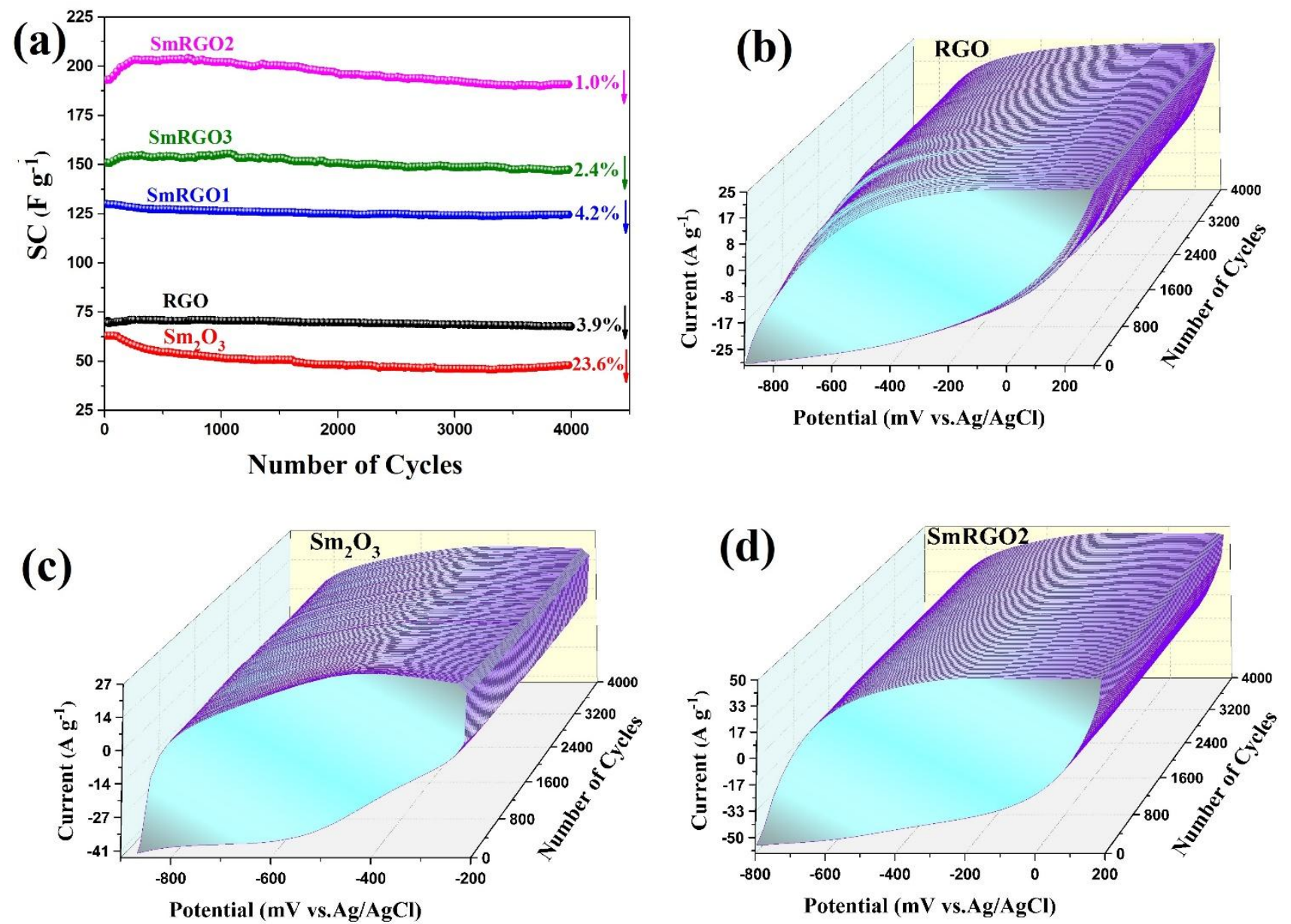

Fig. 6 

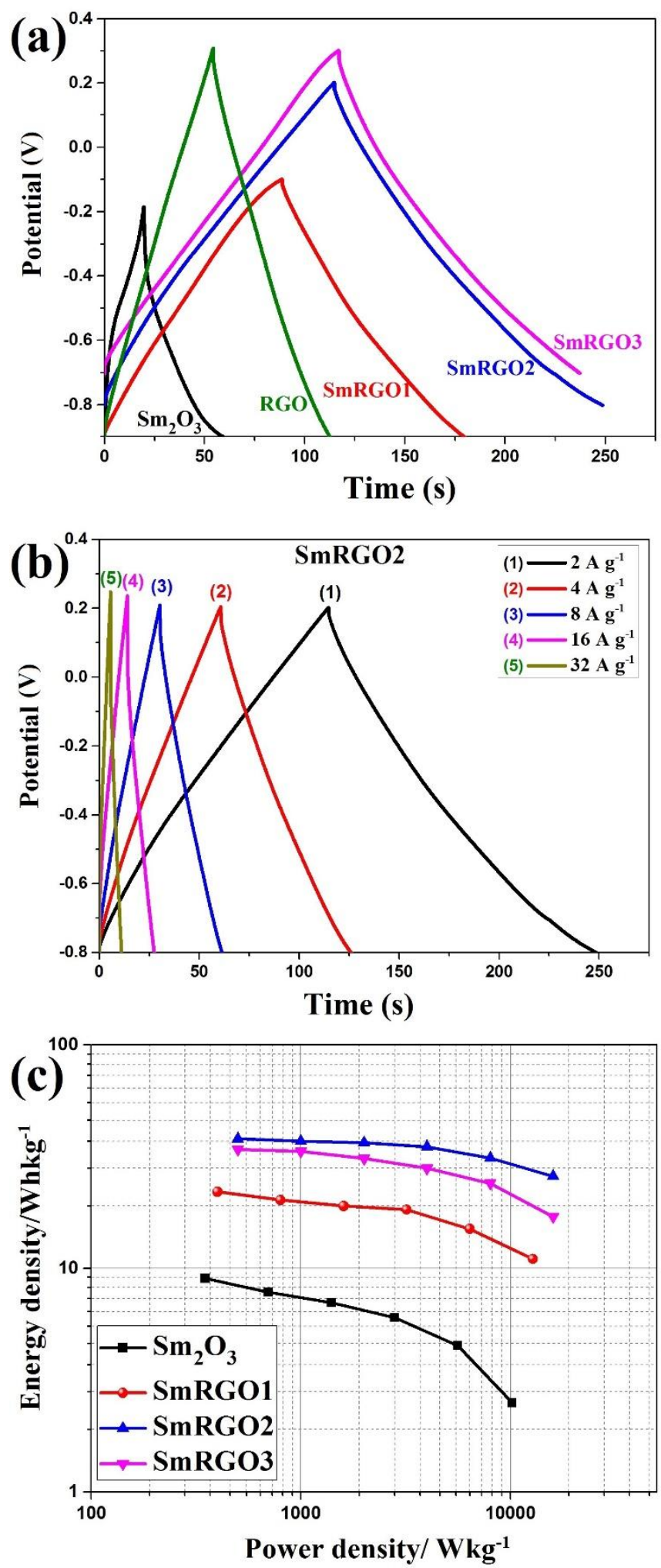

Fig. 7 


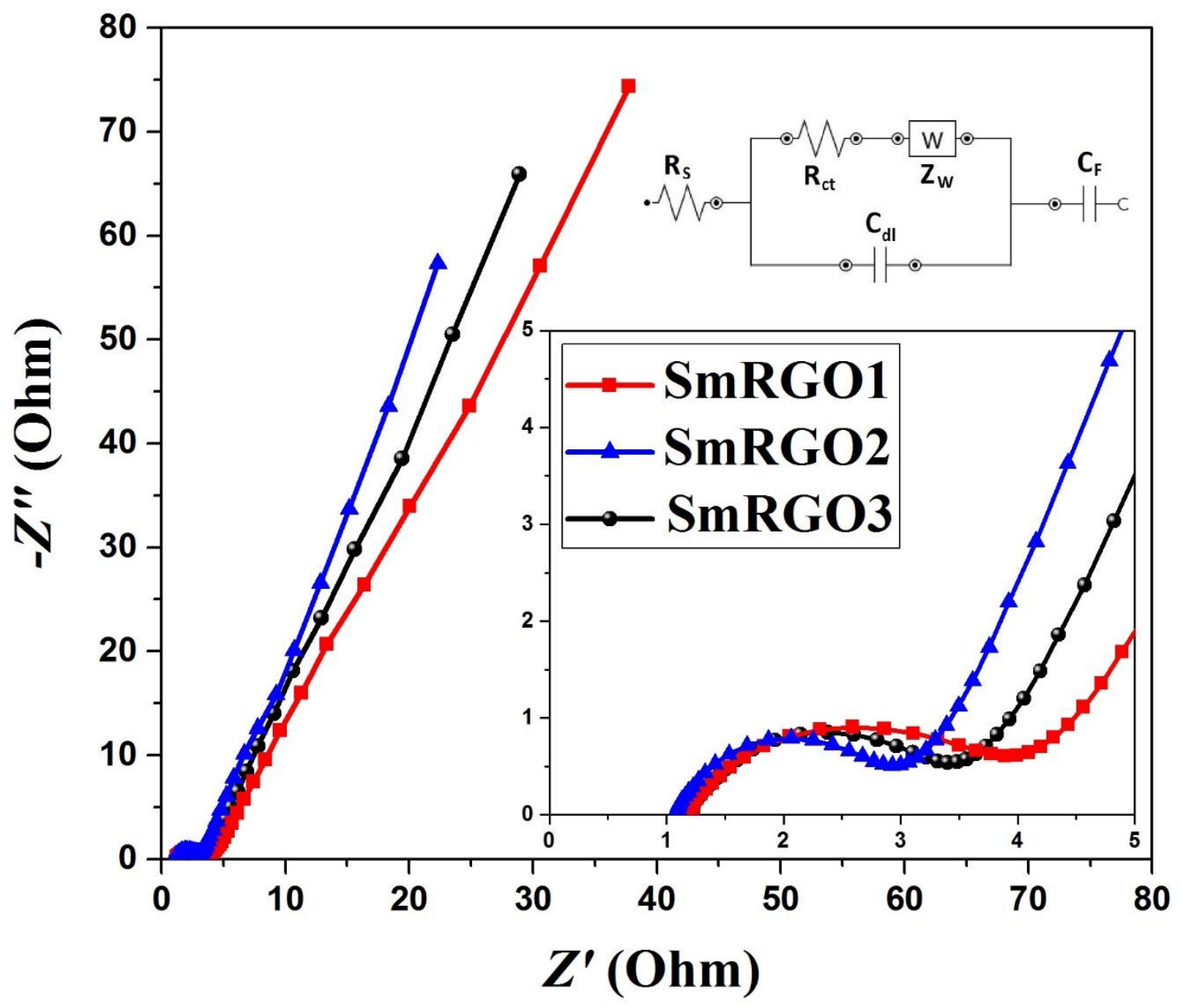

Fig. 8 


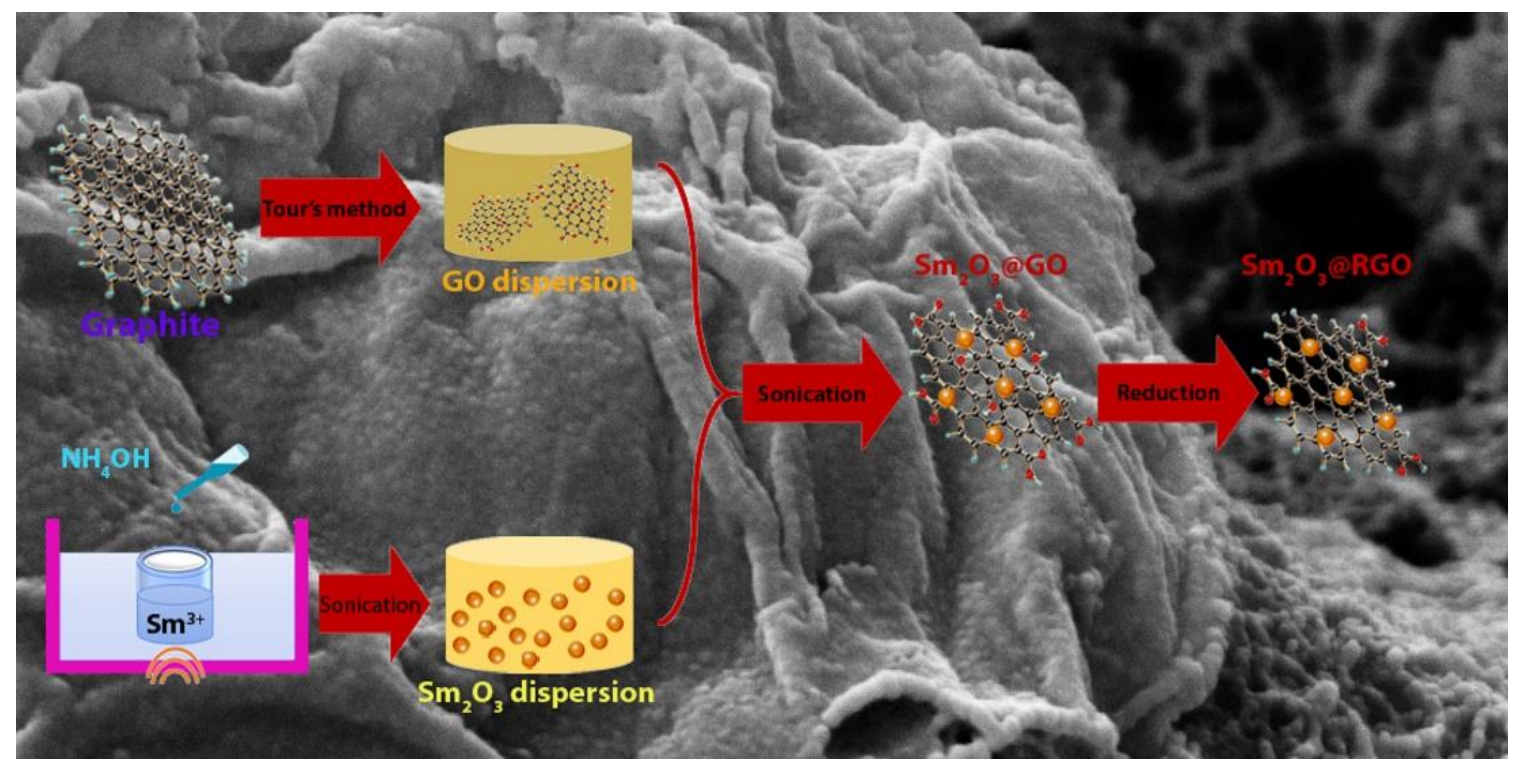

Scheme 1 


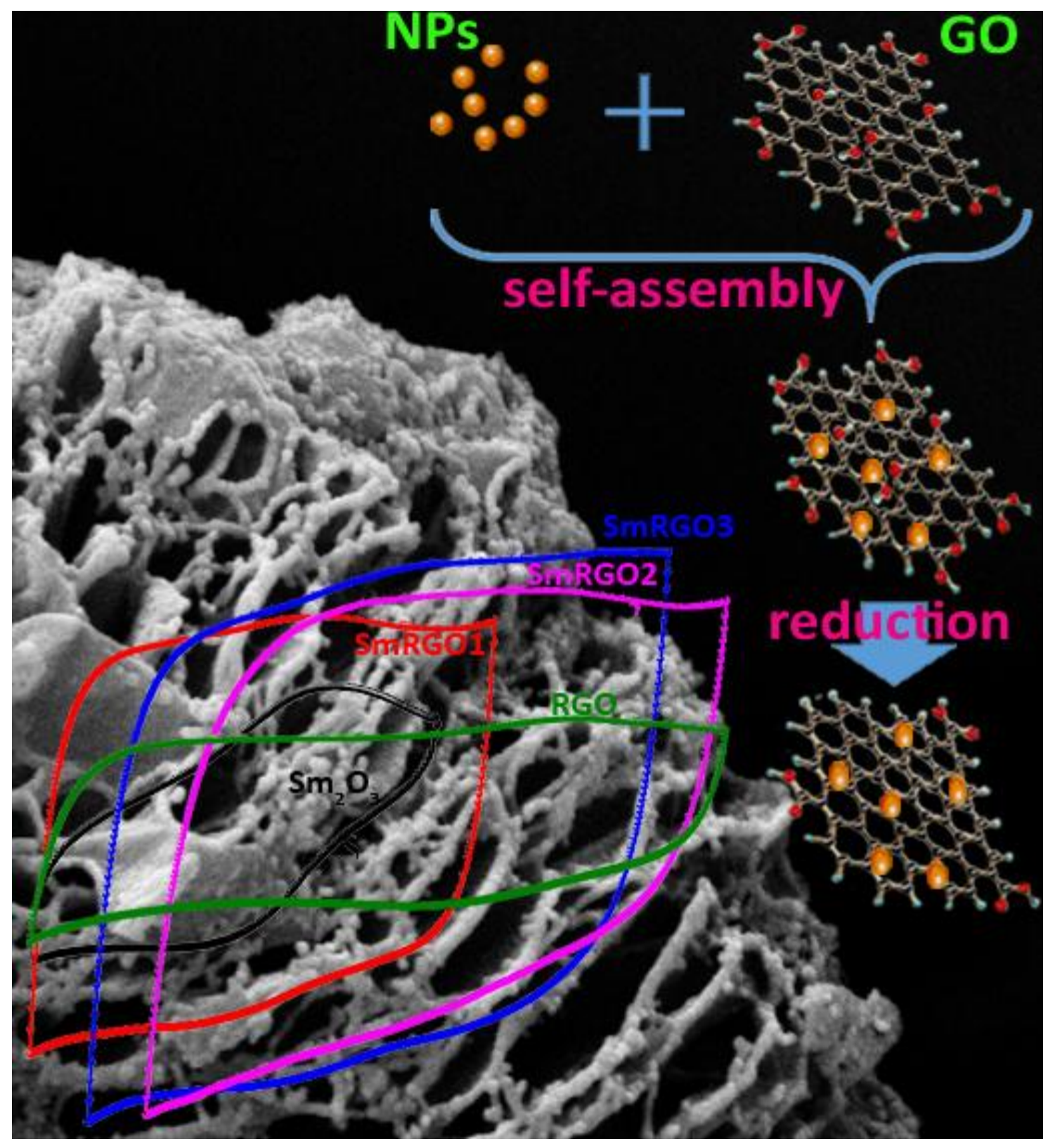

